\title{
Don Juan oder noch eine Figur des Verführers
}

Anders als bei dem Venezianer Giacomo Casanova handelt es sich bei Don Juan - dessen Mythos wiederum im romanischen Süden Europas verortet ist um keine historische Gestalt, sondern um eine literarische Figur, die seit dem frühen 17. Jahrhundert so komplex weiterentwickelt wurde, dass sie eine ungeheure intertextuelle Dichte erworben hat. So kam es zur Ausarbeitung und Ausprägung eines vielverwobenen Don Juan-Stoffes, nicht allein in den Literaturen Europas, sondern in den Literaturen der Welt. Von Casanova unterscheidet Don Juan, dass diese Fiktion des spanischen Verführers deutlich älter ist als unser italienischer Handelsreisender in Sachen Liebe, an dessen realer Existenz freilich lange gezweifelt worden war. Versuchen wir also, uns zunächst einen kleinen Überblick über diesen literarischen Stoff zu verschaffen. Ich stütze mich dabei in jenen Aspekten, die für unsere Vorlesung wichtig sind, auf Elisabeth Frenzels Eintrag in ihrem in den Literaturwissenschaften längst kanonischen Überblicksband. ${ }^{1}$

Der Eintrag von Frenzel beginnt mit dem Hinweis, dass die Gestalt des Don Juan in einer ersten und für die weitere Geschichte dieser Figur fundamentalen Ausprägung in Tirso de Molinas berühmtem Theaterstück El burlador de Sevilla y convidado de piedra das Licht der Welt erblickte. Dieses Stück wurde erstmals im Spanien des Siglo de Oro im Jahre 1613 aufgeführt. In ihm werde die ,unselige Leidenschaft" des Helden und Protagonisten Tirsos, Frauen zu verführen und damit $\mathrm{zu}$ entehren, anhand von vier verschiedenen Frauen vorgeführt: an Doña Isabella, der Don Juan des Nachts als ihr tatsächlicher Liebhaber Octavio erscheint, an Doña Anna, welcher er erneut in den Mantel des Liebhabers gehüllt erscheint und deren Vater Don Gonzalo de Ulloa er im Kampfe ersticht, sowie an zwei Mädchen aus dem Volk, welche er mit windigen Versprechen auf Heirat ködert und seinen Wünschen gefügig macht. Auf der Flucht gelangt er an das Grab Don Gonzalos, dessen Standbild er in seinem Übermut zu sich einlädt. Doch der convidado de piedra erscheint wirklich und überbringt ihm eine Gegeneinladung auf den Kirchhof. Als Don Juan dem steinernen Gast die Hand reicht, verbrennt ihn ein höllisches Feuer.

Die Gründe für die leidenschaftliche Verführungskunst des Don Juan werden bei Tirso de Molina nicht angegeben. Eine psychologische Ausleuchtung der Figur erfolgt bei dem spanischen Dramatiker im Grunde kaum. Sie wirkt allein durch ihr spektakuläres Handeln. Die Ursprünge dieses Stoffes scheinen in volkstümlichen

1 Frenzel, Elisabeth: Stoffe der Weltliteratur. Ein Lexikon dichtungsgeschichtlicher Längsschnitte. 6., verbesserte und um ein Register erweiterte Auflage. Stuttgart: Alfred Kröner Verlag 1983.

Ә Open Access. (C) 2020 Ottmar Ette, publiziert von De Gruyter. (c) BY-NC-ND Dieses Werk ist lizenziert unter der Creative Commons Attribution-NonCommercial-NoDerivatives 4.0 International Lizenz. https://doi.org/10.1515/9783110665093-012 
Überlieferungen $\mathrm{zu}$ liegen, doch wollen wir uns nicht in die unterschiedlichen Thesen verheddern. In jedem Falle geriet Don Juan schnell in einen nicht nur Spanien, sondern bald schon ganz Europa erfassenden Umlauf, so dass sich der Stoff zu einem der lebendigsten und aktivsten in der Geschichte der Literaturen der Welt entwickelte und allein in Spanien, Deutschland oder Frankreich jeweils weit über hundert Bearbeitungen erfuhr. Längst hat er sich über die ganze Welt ausgebreitet.

Bereits an dieser Stelle wird deutlich - und hierauf hinzuweisen ist im Rahmen dieser Vorlesung sicherlich nicht überflüssig -, dass eine rein nationalphilologische Herangehensweise an das Thema Don Juan im Grunde weitgehend irreführend und letztlich absurd ist, da die weltweit beteiligten Autorinnen und Autoren sich in der Tat niemals darum gekümmert haben, ob ihre Bezugstexte aus derselben oder einer anderssprachigen Literatur stammten. Es ist hier nicht der Ort, die Absurditäten einer solchen Sicht literarischer Gegenstände $\mathrm{zu}$ diskutieren! Eine transareale Herangehensweise wäre wohl die adäquateste Lösung. ${ }^{2}$ Die Romanistik ist für eine derartige methodologisch abgesicherte Vorgehensweise zweifellos bestens gerüstet. Doch möchte ich mich beim Don Juan-Stoff im Folgenden nicht ausschließlich auf die Hispanistik und damit den spanischsprachigen Raum beschränken. Eine weltumspannende Erörterung des Stoffes andererseits kann in dieser Vorlesung natürlich nicht geleistet werden. Sie bezieht sich vielmehr auf den gesamten literarischen Komplex des Themas Liebe.

Der weitere Weg des Don Juan verläuft über Italien, wo sich bereits im 17. Jahrhundert mehrfache Bearbeitungen für das Theater finden lassen. Dort ging die für das Theater Tirsos so wichtige religiöse Dimension weitgehend verloren. Italienische Komödianten brachten den Stoff dann nach Frankreich, wo sich die Aufmerksamkeit von den sogenannten lazzi der Handlungsebene wieder zurück auf die Hauptfigur richtete, diese aber in einen brutalen Schurken verwandelte. Eine stärkere Straffung der einzelnen Handlungselemente bei verschiedenen französischen Bearbeitern führt dann zur Theaterfassung von Molière, der in seinem Don Juan ou le Festin de Pierre aus dem Jahre 1665 dem Stoff seine zweite klassische Fassung vermittelte. Mit dieser Fassung werden wir uns in der Vorlesung ebenfalls beschäftigen.

Bei Molière ist unser Don Juan moderner geworden, was sich im Übrigen auch in der langen Rezeptionsgeschichte dieses Stückes aus dem Siècle classique zeigt. wir haben es beim Don Juan Molières mit einer reiferen, selbstreflexiven und gera-

2 Vgl. zur methodologischen Grundlage und Begründung ausführlich Ette, Ottmar: TransArea. Eine literarische Globalisierungsgeschichte. Berlin - Boston: Walter de Gruyter 2012. 
dezu intellektuellen Persönlichkeit zu tun, wie wir noch sehen werden. Die Verführungskünste Don Juans treten bei dem französischen Dramatiker in den Hintergrund: Der reife Schwerenöter hat längst Elvire geheiratet, nachdem er sie aus dem Kloster entführt hatte, sie dann aber verlassen, da ihn der Besitz einer Frau nicht interessiert. Freilich reizt ihn noch immer jede weibliche Schönheit zu einem Eroberungsversuch, den er in militärischer Metaphorik begreift und plant, ohne jedoch an der einmal Eroberten größeres Interesse zu verspüren. Bei Molières Dom Juan wohnen wir einer deutlichen Intellektualisierung bei. Mit Giacomo Casanova verbindet ihn freilich die Tatsache, dass er ein Libertin ist, der sich nicht langfristig über seine Eroberungen zu freuen vermag, sondern ganz und gar dem Libertinage verfallen ist. Nicht nur in Frankreich war Molières Deutung der Gestalt dieses Liebhabers und bösartigen Verführers für weitere Bearbeitungen prägend.

In Spanien wiederum tauchten zwei Motive auf, welche dann die weitere Fortschreibung des Stoffes im 19. Jahhundert stark beeinflussen sollten. Das eine Motiv erinnert an Corneilles Le Cid, denn die verführte Doña Ana verspürt eine deutliche Tendenz, ja Liebe zum Mörder ihres eigenen Vaters. Sollen wir hier von einem Cid-Komplex sprechen? Ich erspare mir an dieser Stelle jeglichen psychoanalytisch eingefärbten Kommentar. Und als zweites Motiv taucht die tiefe Reue des Don Juan auf, welche auch das Moment einer möglichen Erlösung schon früh beinhaltete.

Leichter und luftiger, stärker in der italienischen Tradition stehend, kommt Wolfgang Amadeus Mozarts Don Giovanni mit dem Libretto Da Pontes daher; seine Deutung aus dem Jahre 1787 steht ganz in der Tradition der Opera buffa. In seiner Oper kommt es zu einer Verschmelzung der unterschiedlichen Traditionslinien, wobei sich komische und tragische Elemente die Waage halten. In E.T.A. Hoffmanns Novelle „Don Juan“ werden die moralischen Dimensionen des Don Juan-Stoffes, die seit Tirso de Molinas Stück im Vordergrund standen, wieder deutlicher herausgearbeitet. In dieser Fassung freilich stoßen wir auf einen Don Juan, der als ein von den Menschen Enttäuschter und Betrogener gegen die Menschen und gegen Gott aufbegehrt. Auch das Cid-Motiv wird stärker hervorgekehrt, denn Ana liebt ihn, obwohl er doch der Mörder ihres eigenen Vaters ist. So sehen wir eine deutliche Romantisierung des Don Juan in der ersten Hälfte des 19. Jahrhunderts, die von grundlegender Bedeutung für die weitere Entwicklung seines literarisch tradierten Bildes ist. Die psychologische Dimension der Figur gewinnt an Schärfe.

Die romantischen Autorinnen und Autoren, die sich mit dem Don Juan-Stoff im Drama, in der Erzählung oder im Roman beschäftigten, sind Legion. Ich kann hier nicht auf all diese Entwicklungen eingehen. Gerade das von E.T.A. Hoffmann eingeführte Motiv der Idealsuche entfaltet aber das für die Liebe so grundlegende Element der Erkenntnissuche und des Erkenntnisgewinns, das in vielen Werken zentral gestellt wird. 
Die Mañara-Sage, die auf eine historische Figur aus dem Sevilla des 17. Jahrhunderts zurückgeht, enthielt Elemente, welche sich im 19. Jahrhundert leicht mit dem Don Juan-Stoff verbinden ließen. Denn die Erzählung von einem höchst erfolgreichen Liebhaber, der dann aber durch die Heirat mit einer Frau zum ehrenhaften Leben konvertiert und durch deren Tod zum reumütigen Wohltäter der Armen wird, verknüpfte sich leicht mit der Vorstellung des Idealsuchers, die im 19. Jahrhundert so starke Bearbeitungen auslöste. Don Juan Tenorio von Juan Zorrilla y Moral stellte hier 1844 eine entscheidende Wendung dar, mit der wir uns noch ausführlicher beschäftigen wollen. Dabei wird eine Wette in den Mittelpunkt gerückt, welche um die Verführung einer Nonne kreist, was wiederum sehr stark in ein spanisches Ambiente zurückführt und die Herkunft des Stoffes unterstreicht. Die schöne Inés, die Nonne werden soll, erscheint mitten in Don Juans frevlerischem Tun; die Erschlagung ihres Vaters knüpft wiederum an die alten spanischen Traditionslinien an und führt sie der Romantik gemäß weiter. Nun streckt sich Don Juan nicht länger die Hand des erschlagenen Vaters, sondern jene von Inés aus dem Grabe entgegen; die Verwandlung und Bekehrung des sündigen Don Juan führen die ursprüngliche religiöse Motivation wieder mit starken Zügen ein. So gelangte die romantische Rehabilitierung auf ihren Höhepunkt: Don Juan Tenorio wurde in Spanien und Lateinamerika gemeinhin am Allerseelentag geradezu zeremoniell aufgeführt.

Ich will hier nicht mehr auf die zahlreichen Versuche eingehen, die auf eine Desillusionierung des Don Juan abzielten und etwa einen gealterten oder vor seinem Greisenalter stehenden ehemaligen Frauenhelden zeigen. Nicht umsonst wurde Don Juan im weiteren Fortgang der Stoffgeschichte sogar die Männlichkeit schlechthin abgesprochen und ein effeminierter Don Juan entstand. Ein abgehalfterter oder großväterlicher Don Juan ist für unsere Vorlesung aber nicht mehr von Interesse. Eine fast unendliche Abfolge von psychologisierenden Remotivationen des Don Juan-Stoffes prägt das ausgehende 19. und das gesamte 20. Jahrhundert und zeigt, welche Faszinationskraft er noch immer ausübt. Eine besondere Note verdiente die italienische Rezeption des spanischen Stoffes, bei der ich an dieser Stelle nur Vitaliano Brancatis Don Giovanni in Sicilia stark zur Ferienlektüre anempfehlen will. Don Juan ist ohne jeden Zweifel zu einer durch die Literaturen der Welt beförderten Faszination geworden, die noch immer von dieser Figur des Frauenverführers ausgeht.

Kehren wir nun aber zum Theaterstück des Spaniers Tirso de Molina zurück, der um 1580 in Madrid geboren wurde und 1648 verstarb! In Madrid scheint auch um 1624 die Uraufführung seines Don Juan stattgefunden zu haben, von dem die lange Stoffgeschichte oder Ahnengalerie ausgeht. Wir wollen uns hierbei nicht um die zahlreichen Kontroversen kümmern, die um die Autorschaft von Tirso immer wieder aufflammten: Wichtig ist für uns allein der Stoff und die 
Zentralstellung der Gestalt des männlichen Verführers. Und diese Zentralstellung erfolgt in Tirso de Molinas Stück ganz ohne Zweifel: Seine Figur beherrscht es geradezu. In ihr kommen all jene Traditionslinien aus der Volksliteratur zusammen, welche nicht allein die Herausforderungen an die Adresse menschlicher und gesellschaftlicher Normen, sondern auch an die überzeitlichen göttlichen Gebote thematisierten.

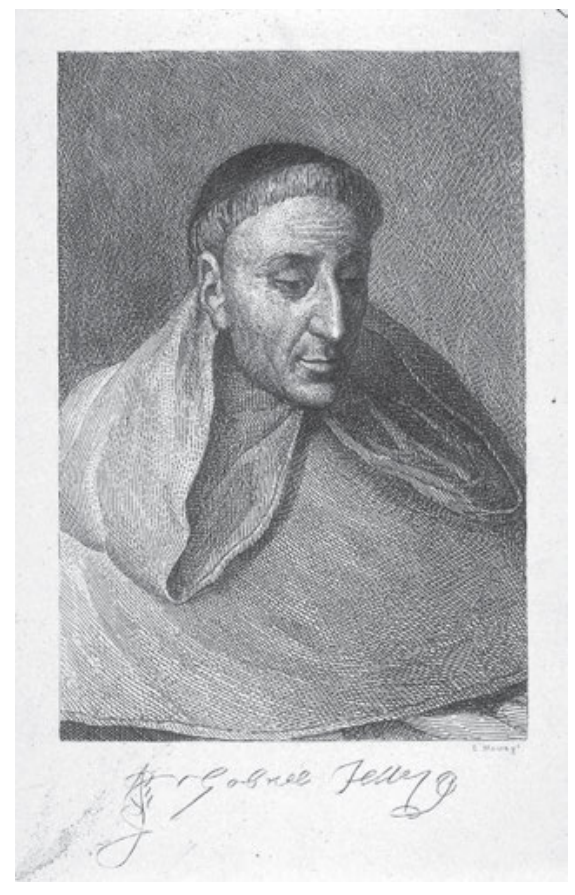

Abb. 68: Tirso de Molina, eigentlich Gabriel Téllez (Madrid, 1579 - Almazán in der Provinz Soria, 1648).

Die Verführung einer Herzogin am neapolitanischen Hof durch den jungen Edelmann Don Juan bildet den Ausgangspunkt dieses Stückes, das diegetisch sozusagen in das spanische Italien verlegt worden ist. Die Rückkehr des Verführers nach Spanien wird gesäumt von der Zerstörung der Unschuld einer jungen Fischerin, wonach sich Don Juan in Sevilla mit einer jungen Edeldame verbindet, deren Vater Don González er jedoch ermordet, als dieser eingreift, um die Ehre der Bedrängten zu retten. Als Don Juan später die Statue des von ihm Ermordeten erblickt und mit der herausfordernden Geste eines frevelhaften Spötters zum Nachtmahl einlädt, erscheint sie auf wundersame Weise zum vereinbarten Termin und lädt ihrerseits ihren Mörder ein, sich zu einem Essen in die Gruft zu begeben. Don Juan lässt sich in seiner Kühnheit nicht erschüttern und nimmt an diesem seltsamen Nachtmahl teil, bei dem Skorpione und Vipern aufgetischt 
werden. Als ihm der Ermordete zum Abschied die Hand reicht, ergreift sie Don Juan unerschrocken und wird erbarmungslos in den Höllenschlund gerissen. So wird der Freigeist, Frevler und Frauenschänder bestraft, die gesellschaftliche Ordnung wieder hergestellt und auch den göttlichen Geboten entsprochen.

Damit bewerkstelligt Tirso de Molina den Spagat zwischen Mantel-undDegen-Drama und religiösem Spiel, das im letzten Teil des Theaterstückes deutlich dominiert. Die göttliche Strafe trifft, wer sich erst bei seinem Tod auf ein göttliches Erbarmen besinnt und zuvor ein lasterhaftes Leben geführt hat. Das Motiv der Höllenfahrt des Don Juan ist in dieser Hinsicht zentral und zeugt von der bildhaften literarischen Kunst des Verfassers wie von seiner didaktisch-christlichen Sendung. Die religiöse Bedeutung von Tirso de Molinas wohl bekanntestem Theaterstück ist offenkundig. Doch seine Grundstruktur bietet - wie bereits betont - für die unterschiedlichsten daran anknüpfenden Traditionen viele Möglichkeiten.

Ich möchte Ihnen gerne in einem kurzen Durchgang einige wenige Beispiele für diese Figur des männlichen Verführers und bestraften Frevlers aus der reichen Literatur dieses Stoffes zeigen, nachdem wir mit Casanova ja bereits die Figur des verführten Verführers kennengelernt hatten. Ein solcher ist nun Don Juan in keiner Weise: Denn er ist unzweifelhaft der aktive männliche Verführer in der Literatur und als spanischer Frauenheld und Frauenschänder als solcher dann erst für die nachfolgenden Abwandlungen und Variationen offen.

Beginnen wir also mit der nachfolgenden Szene aus Tirso de Molinas Burlador de Sevilla! Der nachfolgende Monolog Don Juans stammt aus der siebten Szene im zweiten Akt:

\footnotetext{
Scheint es nicht Zauberei, was hier geschehn?

Mir kommt dieß Briefchen mit der Post der Lüfte!

Gewiß, das Fräulein ist's, das der Marques

Mir so gepriesen hat; sieh nur mein Glück!

Laut nennt Sevilla den Verführer mich;

Und meine höchste Lust von jeher war's,

Ein Weib verführen und entehrt verlassen.

Bei Gott, ich will es öffnen. Erst geh' ich

Ein wenig seitwärts von dem Haus; bedarf's

Hier eine andre Kriegslist noch? Führwahr,

Da muß ich lachen! - Auf diesem Brief!

Er ist an den Marques; das ist ganz klar;

Denn Doña Anna heißt die Unterschrift.

Was schreibt sie?

Liest

„Seines Wortes vergessend, hat

Mein Vater im Geheimen mich verlobt;
} 
Mir half kein Widerstand. Kann ich noch leben, Da er den Tod mir gab? Wenn nach Gebühr Du meine Lieb' und meinen Willen achtest, Und deine Liebe wahr ist, zeig es nun! Auf daß du siehst, wie ich dich schätze, komm In dieser Nacht ans Thor; es soll dir, Vetter, Um elf geöffnet sein: so wirst du dann Das Ziel erlangen deiner Lieb' und Hoffnung.

Zum Zeichen für Leonorilla und Die Dienerinnen, Theurer, hülle dich In einen rothen Mantel. - Meine Liebe Baut nur auf dich, mein unglücksel'ger Freund!“ Wie sich das fügt! Der Spaß giebt mir zu lachen. Bei Gott, mit gleicher List und Täuschung will Ich sie erobern, so wie Isabella

Einst Neapel. ${ }^{3}$

In dieser Szene verkündet Don Juan stolz seinen Spitznamen in Sevilla, El Burlador oder - nicht ganz zutreffend zu übersetzen - „der Spötter“. Sein Ziel ist es stets, die von ihm ins Visier genommenen Frauen zu verführen, mit ihnen zu schlafen und sie dadurch buchstäblich ihrer Ehre zu entkleiden. Was mit diesen Frauen hernach geschieht und in welche geistigen oder religiösen Abgründe er diese entehrten Frauen stürzt, bleibt dem Burlador, dem Spötter, letztlich gleichgültig: Er will nur seinen Spaß haben.

Eine burla zielt als Spott auf ein bewusstes Hinters-Licht-Führen des Anderen, der dem Gelächter seiner Mitmenschen preisgegeben und ausgesetzt wird. Dies macht deutlich, dass es vor allem diese soziale Komponente ist, die eigentliche Entehrung der Frauen, welche Don Juan immer wieder sucht. Zugleich sollten wir nicht vergessen, dass in der Figur Don Juans - und gerade im Kontext der burla die Frage von Wissen und Macht gestellt ist. Denn eine burla beruht auf einem Wissensgefälle: Don Juan weiß über sich, aber auch über Doña Ana Bescheid, während diese nur über sich selbst, nichts aber von Don Juan weiß. Die Asymmetrie der Beziehungen beruht auf einer Asymmetrie des Wissens. In Don Juans Falle zugleich aber auch auf einer Asymmetrie des Liebens. Dass diese Situation freilich auch für Don Juan selbst zur Falle wird, ist zu Beginn der Handlung noch nicht absehbar.

Noch einmal: Dieses Wissensgefälle ist eine wesentliche Voraussetzung der burla und zugleich auch des Verhaltens von Don Juan. Er erfährt in dieser Szene aus einem geheimen Briefchen von der nicht weniger geheimen Liebe Doña Anas

3 Tirso de Molina: Der Spötter von Sevilla und der steinerne Gast. Übersetzt von Ludwig Braunfels. Hg. von Karl-Maria Guth. Berlin. Contumax 2016, S. 50f. Das originalsprachige Zitat im Anhang aus Tirso de Molina: El Burlador de Sevilla. Buenos Aires: Ediciones Colihue 2008, II, 7, S. 74. 
und macht sich diesen Wissensvorsprung zunutze. Schon im Königreich Neapel hatte er zuvor die schöne Isabela täuschen können, indem er frech in die Rolle ihres eigentlichen Liebhabers geschlüpft war. Genau diese Strategie wird er auch hier wieder zur Anwendung bringen, wobei es ihm weniger um die Frauen selbst geht - schon gar nicht um eine länger- oder mittelfristige Beziehung zu einer bestimmten Frau -, sondern um den Genuss, die Lust an der Zerstörung ihrer Ehre, ihres guten Leumunds. Dies aber zielt auf die soziale, die gesellschaftliche Dimension der Liebe, die für den Spanier im Mittelpunkt steht. Es geht Don Juan bei Tirso de Molina um einen größtmöglichen Schaden bei den Opfern seiner burla: Der Frauenverführer ist ein Frauenverspotter.

In der angeführten Passage spielen Liebe, Gesellschaft und Individuum ein geradezu verzweifeltes Spiel, da die Gesellschaft und deren Vertreter - einschließlich des Vaters der schönen Frau - Normen und Verhaltensmuster vorgeben, die nicht zu erfüllen sind. Sie überfordern daher das einzelne Individuum und bedrohen es im Falle einer Nicht-Erfüllung dieser Normen mit völliger gesellschaftlicher Zerstörung. Eben dies macht sich Don Juan zunutze.

Die einzige gesellschaftlich akzeptierte Form der Liebe ist die der christlichen Ehe, wobei die Ehepartner von den Eltern - und insbesondere den Vätern - einander zugeführt und miteinander verheiratet werden. Es ist wohl überflüssig, dies ausführlicher zu erläutern, zu präsent ist uns dies selbst heute noch! Für unsere Fragestellung ist aufschlussreich, dass sich Don Juan als Verführer genau diese insbesondere auf den Frauen lastende Zwangssituation zunutze macht, indem er ungerührt mit dem Eheversprechen, das er immer wieder vor sich herträgt, zu seinem Ziel zu gelangen sucht. Mit seiner Strategie ist er im Grunde höchst erfolgreich und deckt damit - zumindest aus heutiger Sicht - ein gesellschaftliches Manko auf. Denn der burlador macht sich stets und vor allem über die gesellschaftliche wie die göttliche Ordnung lustig, indem er sich - gleichsam iberisch anarchisch - über sie hinwegsetzt und sie kühn herausfordert.

Dabei gibt es von seiner Seite weder Mitleid mit den von ihm getäuschten oder verführten Frauen noch mit deren getäuschten, betrogenen oder getöteten Liebhabern oder Vätern. Das Begehren Don Juans ist ohne jeden Zweifel grundlegend gesellschaftszersetzend, zielt auf ein Unterlaufen der sozialen Normsetzungen ab, wird aber - wie es der gegebene Spitzname El burlador belegen mag - selbst wiederum vom jeweils schadenfrohen Teil der Gesellschaft mit Amüsement goutiert. Denn die burla und der burlador benötigen auch ein Publikum, das zumindest insgeheim den Listen Don Juans applaudiert.

Liebe wird in diesem Zusammenhang zu einer Abfolge von Stratagemen, die natürlich - wie die Quiproquos - auf der Theaterbühne leicht in Szene zu setzen sind. Don Juan ist dabei jener Typus eines männlichen Verführers, der gerne bereit ist, Kopf und Kragen für seine Abenteuer zu riskieren, wobei es ihm 
nicht um eine wechselseitige Liebe geht, sondern um die Durchsetzung seiner einseitig, asymmetrisch beschlossenen Pläne und seines festgelegten Ziels, eine Frau zumindest kurzzeitig in Besitz sowie unter seine Verfügungsgewalt zu bringen und - einmal entehrt - wieder zu entlassen, also der gesellschaftlichen Verachtung, dem Lachen preiszugeben.

Gegenüber der schönen Aminta schwört Don Juan in siebten Szene des dritten Aktes von Tirso de Molinas El Burlador de Sevilla - wie gegenüber anderen Frauen - ewige Treue, doch muss er ihr zugleich auch versichern, dass er sich wünsche, ein Mann solle ihn töten, wenn er sein Wort ihr gegenüber brechen würde. Gesagt, getan! An eben dieser Stelle des Theatertextes wird sich das gegebene Wort Don Juans gleichsam in ein göttliches Wort verwandeln, welches wie ein Boomerang zu dem spanischen Spötter zurückkehren und seinem Leben ein Ende bereiten wird.

Das Eingreifen Gottes am Ende, gleichsam in Form eines Wunders, führt die zweite, die christlich-katholische Dimension in das Theaterstück ein, das letztlich die Durchsetzung dieser christlichen und religiös fundierten Auffassung von Liebe bestätigt. Wenn Sie so wollen, haben wir in Don Juan immer noch den Kampf zwischen einer christlich sanktionierten Liebeskonzeption und einer diese bekämpfenden Liebesauffassung, zwischen rechtem Glauben und Häresie sowie den damit einhergehenden Konflikten um Konvivenz vor uns. Albi und die Albigenserkriege liegen förmlich in der Luft und die gesellschaftliche Schlüsselfunktion der Liebesauffassung ist evident.

Wie bereits in den Ausführungen von Denis de Rougemont in seinem L'amour et l'Occident begreifen wir, dass Liebe sehr wohl mit Religion, mit Glaube und religiösen Normen, in einer intimen und gesellschaftlich signifikanten Verbindung steht. Dies wird auch und gerade an der Figur Don Juans sehr deutlich und vermag damit die These des Schweizer Kulturhistorikers und Essayisten $\mathrm{zu}$ bestätigen. Die Liebe ist eine gesellschaftliche Kraft allererster Güte: Ihre Ordnung steht mit der Ordnung der Gesellschaft in einer intimen Wechselwirkung.

Doch wie ist all dies sprachlich umgesetzt? Im Don Juan-Stoff ist die militärische Sprache stets präsent, ja bisweilen erscheint Tirso de Molinas Stück in heutigen Aufführungen wie auch in der Tradition der Mantel- und-Degen-Stücke als ein Katalog von Kriegslisten, welche in der Sprache von Eroberungen und Plünderungen ausgeführt werden. Hierbei kommen dem Zuschauer die Heldentaten des Don Juan und seine beeindruckende Unerschrockenheit und Tapferkeit im Grunde wie Episoden im quasi militärischen Kampf gegen die Nebenbuhler, tatsächlichen Liebhaber oder Väter vor, wie die heldenhafte sowie strategisch erfolgreiche Finte gegen die gesellschaftlich rechtmäßigen patriarchalen Besitzer der von ihm ins Auge gefassten Frauen. Sein Kampf ist ein individueller, 
gleichsam anarchistischer Kampf gegen die Grundfeste der katholischen spanischen Gesellschaft.

Gehen wir an dieser Stelle über vom spanischen Siglo de Oro in das französische Siècle Classique mit seinen gesellschaftlich so differenten, aber ebenso autoritären Normsetzungen im 17. Jahrhundert. In seiner literarisch feinen Gestaltung der Figur des Don Juan, seiner comédie mit dem Titel Dom Juan, hat Molière es in Frankreich auf einzigartige Weise verstanden, diese militärische Sprache auf die Eroberungen der Schönen selbst zu beziehen und damit die Sprache der Liebe mit der Sprache der Kriegsführung so intensiv wie kaum ein anderer zu verquicken. Sein Dom Juan ou le festin de pierre ist daher auch für uns eine kurze Beschäftigung unter diesen Gesichtspunkten wert.

Versuchen wir zunächst, kurz ein allgemeines Bild dieser Auseinandersetzung mit dem Don Juan-Stoff vor dem Hintergrund der bereits skizzierten Stoffentwicklung zu zeichnen. Die Komödie in fünf Akten des 1622 in Paris geborenen und dort 1673 verstorbenen Molière wurde am 15. Februar 1665 in der französischen Hauptstadt im Palais Royal uraufgeführt. Anders als vor ihm die italienischen Bearbeiter des Stoffes interessierte sich Molière wenig für die komödiantischen und handlungsspezifischen Aspekte, sondern legte seinen Don Juan in einer mitunter geradezu modern wirkenden vielschichtigen Psychologie an. Molière griff auf viele Episoden auch früherer französischer Theaterleute zurück, stellte seinem Don Juan aber eine intelligente Frauengestalt, die kluge Elvira, gegenüber und beleuchtete ihn dadurch aus doppeltem Blickwinkel. Der durchaus von Molière mit positiven Attributen ausgestattete atheistische Freigeist täuscht christliche Reue und Bekehrung vor, doch weiß der Zuschauer um Don Juans Heucheln, da dieser sich seinem Diener Sganarelle - wie oft bei dem französischen Klassiker eine stark konturierte Figur - offenbart. Don Juan wird zu einem hintersinnigen Libertin, der sein Tun reflektiert und durch seine Eleganz besticht. Erst der fünfte Akt zeigt den französischen Don Juan als Häretiker und ruchlosen Individualisten, der sich keiner Ordnung unterwirft und aus gutem Grunde am Ende seine Höllenfahrt anzutreten hat. Gegen die Normen von Gesetz und Religion setzt er die freigeistigen Formen eines Lebens, das sich jeglicher Ordnung zu entziehen sucht und sich hinter den Stratagemen beständigen Heuchelns - ein weiteres großes Molière'sches Thema - versteckt.

Die gegen die christliche Religion gewendeten Sätze Don Juans, die teilweise der Zensur zum Opfer fielen, weisen ebenso die Selbstreflexion wie auch das Selbstbewusstsein des noch immer kühnen Titelhelden auf. Wie schon gegen seinen Tartuffe, so erhob sich auch gegen Molières Dom Juan eine geharnischte Querelle, die für den französischen Bühnendichter vielfältige Gefahren barg. Doch noch schützte ihn der französische König, noch schützte ihn der absolute Herrscher Louis XIV. vor allen Angriffen klerikaler wie auch bühnenspezifischer 

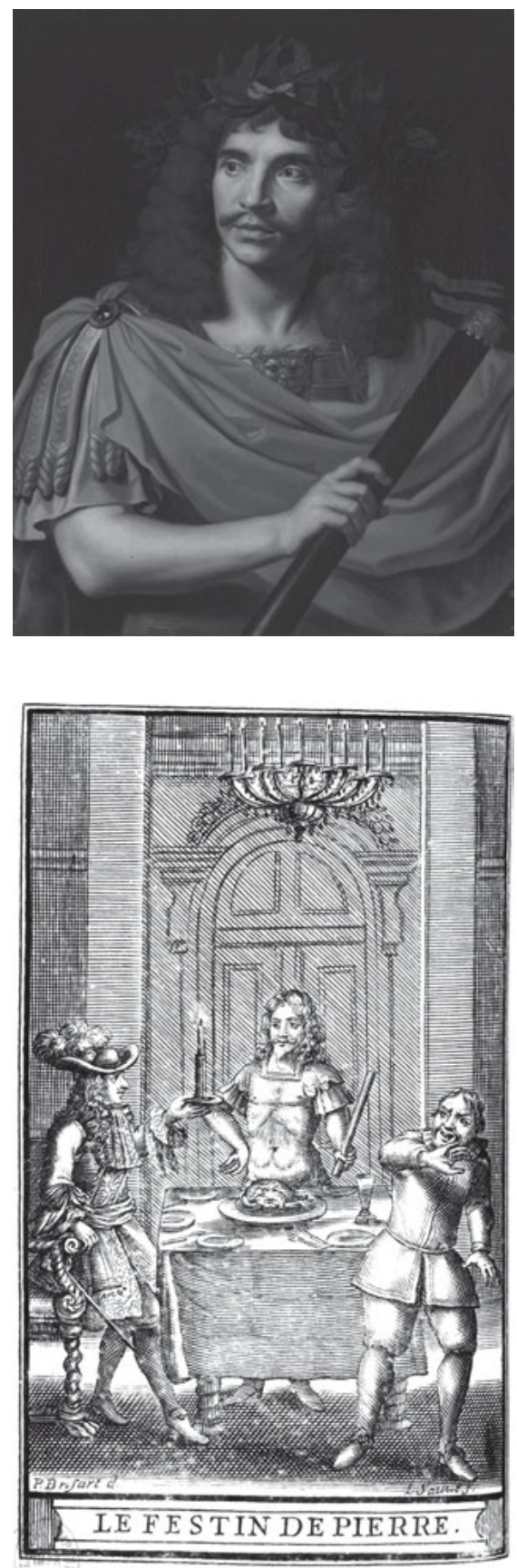

Abb. 69: Molière, eigentlich Jean-Baptiste Poquelin (Paris, 1622 - ebenda, 1673), in der Rolle des Julius Caesar im Stück La Mort de Pompée von Pierre Corneille.
Abb. 70: Frontispiz zu Molières Dom Juan ou le festin de pierre. 
Art, kritisierte man doch an dieser Komödie, dass sie Elemente des Tragischen in die comédie gemischt und gegen die in Frankreich gültige klassische Regelpoetik verstoßen habe. Doch vielleicht sind es zusammen mit der höchst hintergründigen Gestaltung der Dienerfigur Sganarelle diese Elemente, welche uns noch heute Molières Deutung des Stoffes als modern erscheinen lassen. Aus einer gänzlich anderen Perspektive als bei Tirso de Molina erscheint auch bei Molière die gesellschaftliche Relevanz und Bedeutungsmächtigkeit der Liebesvorstellungen in starkem, gleißendem Licht.

Auch wenn ich an dieser Stelle nicht ausführlich auf das Bühnenstück des französischen Theaterschriftstellers eingehen kann, so möchte ich doch einige wenige und für uns wichtige Aspekte dieser Fassung hervorheben. Uns interessiert im Kontext der Vorlesung vor allem die Sprache des Liebesdiskurses von Dom Juan, der - dies lässt sich zweifellos behaupten - mit seinen Auffassungen auch nicht hinterm Berg hält und mehrfach sprachlich vorzüglich seine Theorie der Liebe, oder besser der Liebespraxis, dem interessierten Theaterpublikum vor Augen und zu Ohren führt. So erklärt er bereits in der zweiten Szene des ersten Aktes dem Sganarelle, der das Vorgehen seines Herren zunächst verdammt, einige der Grundlagen seiner Auffassung von der Liebe in beredten Worten:

Wie? Du willst, dass man sich an das erste einnehmende Wesen bindet, ihr zuliebe der Welt entsagt und für keine andere mehr Augen haben soll? Das ist eine schöne Sache, sich zu der zweifelhaften Ehre des Treuseins aufzuschwingen, sich für immer in einer einzigen Leidenschaft einzusargen und schon in der Jugend sich für alle anderen Schönheiten tot zu stellen! Nein, nein; Beständigkeit ist die Tugend der Dummköpfe. Alle Schönen haben ein Recht darauf uns zu bezaubern und der Vorteil, uns als erste begegnet zu sein, darf die berechtigen Ansprüche der anderen auf unser Herz nicht schmälern. Was mich betrifft, so reizt mich die Schönheit, wo ich sie finde und ich erliege leicht dieser sanften Gewalt, mit der sie uns anzieht. Mag ich auch gebunden sein, so verpflichtet mich die Liebe zu der einen Schönen nicht dazu, allen anderen Unrecht zu tun.

Meine Augen erkennen sofort die Vorzüge jeder einzelnen und ich erweise ihr dafür die Ehre und zahle den Tribut, den uns die Natur abverlangt. Wie dem auch sei, ich kann mein Herz keiner verweigern, die mir liebenswert erscheint. Und wenn ein schönes Gesicht mein Herz begehrt, und ich zehntausend Herzen hätte - ich gäbe sie alle freudig hin! Die aufkeimende Neigung hat doch immer wieder ihren unerklärlichen Reiz und das reine Vergnügen in der Liebe liegt im Wechsel. Welch unbeschreiblicher Genuß, das Herz einer jungen Schönheit durch hunderterlei Liebesdienst zu bestürmen, Tag für Tag die kleinen Fortschritte zu bemerken, die man macht ... mit Beteuerungen, Tränen und Seufzern die unschuldige Scham einer Seele zu bekämpfen, die sich sträubt, die Waffen zu strecken, Schritt für Schritt die kleien Widerstände aus dem Weg zu räumen, die sie uns entgegenstellt, die Skrupel zu überwinden, die ihr zu Ehre gereichen und sie langsam aber sicher dahin zu bringen, wo man sie haben will. Aber ist man erst einmal ihr Gebieter geworden, ja, was gibt es dann noch zu sagen, was gibt es da noch zu wünschen? Das Schöne an 
der Leidenschaft ist vorbei und wir schlafen ein in dieser Art Liebe, wenn nicht ein neues Objekt der Begierde unsere Sehnsüchte weckt und unserem Herzen seine Reize zur Eroberung anbietet. Schließlich ist nichts süßer, als über den Widerstand einer Schönen zu triumphieren und ich habe auf diesem Gebiet den Ehrgeiz der großen Eroberer, die unablässig von Sieg zu Sieg eilend außerstande sind, ihre Wünsche zu zügeln. Nichts kann den ungestürmen Drang meines Begehrens aufhalten: ich fühle in mir ein Herz, daß die ganze Welt lieben will; und wie Alexander wünschte ich, es gäbe noch andere Welten, auf die ich meine Feldzüge der Liebe ausdehnen könnte. ${ }^{4}$

Ich habe Ihnen absichtsvoll diese gesamte Passage aus dem Dialog zwischen Sganarelle und Dom Juan alias Don Juan vorgestellt, weil in diesem Zitat in dichter Folge doch eine ganze Reihe aufschlussreicher Aspekte für den Diskurs und die Sprache der Liebe aufgelistet sind. Denn zum einen ist bemerkenswert, wie stark die Bedeutung der Augen - gleich zu Beginn dieser Passage - hervorgehoben wird. Don Juan, dies ist unverkennbar, ist ein Augenmensch. Ihm tritt und steht vor Augen, was er begehrt: Seine Lust ist eine Lust der concupiscentia oculorum.

Nun wissen wir aber spätestens seit Helmuth Plessner, dass die Augen ein Fernsinn sind, also aus der Entfernung die Gegenstände abtasten, ohne sie zu berühren und zugleich auch, ohne dass etwas in unseren eigenen Körper zusätzlich eindringt. So ist der Gesichtsinn - wie der optische Kanal auch genannt wird der körperfernste Sinn überhaupt. Über die Augen wird ein Begehren erzeugt, dass auf andere menschliche Sinne, auf das Tasten, in den Mund nehmen, auf unsere Haut und unsere Haare gerichtet ist. Doch genau von diesem distantesten, entferntesten und unkörperlichsten Sinn der menschlichen Natur, des menschlichen Körper-Leibes, gehen das Begehren und die Liebe aus. Durch die Augen entzündet sich auch bei Don Juan, wie er selbst betont, die Liebe. Daher spielt selbstverständlich die Schönheit des geliebten Objekts eine große Rolle, und natürlich auch das Gesicht, auf das sich der Gesichtssinn ja zuallererst zu heften scheint. Don Juan und das, was er seine „Natur“ nennt, werden erregt durch den Anblick der Schönen, die zuerst mit dem Gesichtssinn abgetastet werden, lange bevor andere Sinne aktiv werden.

Wir stellen folglich fest: Die Liebe unseres Don Juan ist auf der sinnlichen Ebene zuallererst ein Oberflächenphänomen. Auf diese Weise wird auch die Passion, die Leidenschaft angeregt, die es als eine Ungerechtigkeit erachten würde, nur von einem Liebesobjekt und nicht von unendlich vielen angesprochen zu werden. Die Aussagen des Don Juan sind auf diesem Gebiet eindeutig und

4 Molière, Jean Baptiste: Don Juan oder Der steinerne Gast. Komödie in fünf Akten. Deutsch von Karin Drechsel. Berlin: Felix Bloch Erben 1980, I, 2, S. 5. Originalzitat im Anhang aus Molière: Don Juan, ou Le Festin de pierre. Texte établi par Charles Louandre. In (ders.): Oeuvres complètes, tome II. Charpentier 1910, I, 2, S. 65 f. 
lassen sich auch mit modernen Liebesaufforderungen in Verbindung bringen, wie sie etwa im Jahre 1970 das Quartett Crosby, Stills, Nash \& Young melodisch zu Gehör brachte: If you can't be with the one you love, love the one you're with.

Die durch das Auge und den Augenblick ausgelösten Leidenschaften des Don Juan richten sich zwar unverkennbar gegen die christliche Liebes- und Eheauffassung, aber haben andererseits nichts oder wenig mit dem Leiden und der Passion zu tun. Nein, der Don Juan Molières ist ganz bestimmt kein an der Liebe Leidender und Verzweifelnder. Wir dürfen hier also feststellen, dass gleichsam neben Denis de Rougemonts amour-passion eine weitere, ebenfalls häretische Liebeskonzeption getreten ist, jene der sukzessiven Polygamie oder des amour-en-série.

Allerdings liegen die Dinge - wie stets in der Liebe - nicht ganz so einfach, sondern komplizierter. Denn es gibt eine Reihe von Überschneidungen mit der höfischen Liebe im Sinne von Denis de Rougemont. Don Juan macht nämlich deutlich, dass der handlungsreiche und in militärischer Diktion beschriebene Eroberungsprozess und nicht etwa die erfüllte Liebe in geteilter Zweisamkeit den eigentlichen Genuss und Anreiz bildet.

Dies aber lässt sich sehr wohl mit jenem Genuss an einem (unerfüllbaren) Begehren in Verbindung bringen, das in der Liebe zu einer hochgestellten Dame ohne Gnade gleichsam von vorneherein nicht nach Erfüllung im Sinne einer konkreten Verkörperlichung streben konnte. Just an diesem Punkt freilich ist an die Stelle der Leidenschaft, immer neue Ausdrucksformen und Positionen dieses Leidens lyrisch darzustellen, die Leidenschaft des Taktikers und Strategen getreten, der die zu erobernde Frau als vorübergehende, austauschbare Kriegsbeute und damit letztlich als einen beliebigen Gegenstand betrachtet.

Im Übrigen ließe sich diese Beziehung innerhalb der abendländischen Kulturtradition auch aus der umgekehrten Perspektive nachweisen. So haben die Konquistadoren, die Kolonialherren wie die Kolonisten aller abendländischen Länder die Kolonien stets als Frauen metaphorisiert, die es zu erobern und zu unterwerfen, aber danach auch auszubeuten gelte. ${ }^{5}$ Bei ihnen geht es nicht um die Liebe, sondern um die Eroberung und Unterwerfung; doch wird das eroberte Land, die Stadt oder das Volk in die Metaphorik der Frau gekleidet, um damit die Eroberung wie die eroberte Beute anschaulich zu machen.

Leidenschaftlich ist an der Liebe Don Juans also vor allem dieser Aspekt, sozusagens das Vorspiel der Taktik und vor allem der Strategie, die zur Eroberung führen. Der Erfolg wird vom Don Juan Molières also durchaus anvisiert und angestrebt: Es geht nicht um strategische Vorspiele um des Vorspiels willen, sondern

5 Vgl. hierzu Hölz, Karl: Das Fremde, das Eigene, das Andere. Die Inszenierung kultureller und geschichtlicher Identität in Lateinamerika. Berlin: Erich Schmidt Verlag 1998. 
um den Prozess der schrittweisen Eroberung, der eindeutig im Zentrum des Begehrens steht. Damit kommt auch wieder das bereits bei Giacomo Casanova betonte quantitative Element zum Tragen. Vergessen wir darüber im Übrigen nicht, dass Molières Don Juan soviel Liebe in sich spürt, um die gesamte Welt zu umarmen und zu lieben. Auch auf dieser Ebene besitzt er eine gemeinsame Metaphorologie mit jenen Eroberern, die wie Alexander der Große am liebsten die ganze Erde unterwerfen würden.

Diese Art der leidenschaftlichen Passion ist nicht auf ein einzelnes Liebesobjekt gerichtet und folglich insgesamt auch nicht auf Ewigkeit gestellt. Vielmehr gehen unserem Molière'schen Don Juan - ganz wie Alexander dem Großen leicht die zu erobernden Objekte der Liebe aus. Denn das Prinzip der (auf Quantität setzenden) Liebe ist - und Albert Camus wird dies später ausbauen - der ständig wiederholte Neubeginn, die ständig neu ins Blickfeld rückende und zum Objekt der Unterwerfung werdende Frau. Dergestalt kann Don Juan auch leicht zum Sisyphus werden, der immer wieder von neuem anfangen muss.

Dabei bieten sich ihm die Gegenstände der Eroberung von selbst an, und er erkennt ihnen das Recht zu, sich erobern zu lassen. Ist dies eine Art Frauenrecht, das es den Frauen erlaubt, die Männer aus monotonen und monogamen Situationen herauszuholen? Diese weitghehend stereotype Rolle der Frau beschränkt sich freilich darauf, gleichsam optisch das Begehren des Helden und Kriegers auszulösen und ihm in der Folge die Eroberung so schwer als irgend möglich zu machen. Doch der Fall der Frau, ihre Verwandlung in ein ,gefallenes‘ Mädchen, steht aus der Perspektive Don Juans immer schon fest. Es ist allein eine Frage der Strategie, bis es zu diesem Punkt kommt.

Im Don Juan-Stoff ist zugleich immer schon die Dimension des Zufalls und der Zufallsbegegnung enthalten und gegenwärtig. Hierbei ist nicht von der wechselseitigen Bestimmung der Liebenden füreinander die Rede, sondern eher vom Zufall, der die Liebenden zufällig zusammenführt. Gerne wiederholen wir unsere Feststellung: Gelegenheit macht Liebe, wie man hier auch sagen könnte. In jedem Falle ist der Zufall hochproduktiv. Seine Valorisierung ermöglicht etwa eine offene Kette und Abfolge von Bekanntschaften und Liebesverhältnissen, also den amour-en-série, der zweifellos eine quantitative Komponente besitzt. Denn wenn einmal der Zufall zugeschlagen und eine Zufallsliebe entzündet hat, gibt es für Don Juan keinen Grund, warum dem künftig Tür und Tor verschlossen sein sollte. Er steht für alle denkbaren und begehrlichen Liebesverhältnisse gleichsam in einer latenten Standby-Funktion, bereit, jederzeit als Frauenverführer in Aktion $\mathrm{zu}$ treten. Der Don Juan Molières ist in dieser Hinsicht näher an den Casanova der Memoiren gerückt.

Für den französischen Theaterschriftsteller ist gewiss nicht im Sinne der höfischen Liebe, wohl aber im Sinne des gesellschaftlichen Lebens am Hofe 
und in der Stadt, in la cour et la ville, ${ }^{6}$ wichtig, sich nicht der Welt gegenüber $\mathrm{zu}$ verschließen. Entsprechend sind gemäß der für das französische Siècle Classique gültigen Regelpoetik die Konstellationen des honnête homme in die Sprache wie vor allem die Beziehungen zwischen seinen Theaterfiguren übersetzt. Molières Figuren entsprechen den Normen und Usancen dieser französischen Gesellschaft von la cour et la ville. Dass dies der katholischen Kirche und ihren entsprechenden Institutionen sowie deren Vertretern am Hofe von Versailles nicht gleichgültig sein konnte, so dass die Liebe sowie verschiedene Liebeskonzeptionen bis hin zum Libertinage wiederum in einen gesellschaftlichen Konflikt mit der Kirche hineingezogen wurden, sollte Molière - der sich der Problematik sehr wohl bewusst war - mehrfach am eigenen Leibe erfahren. Entscheidend freilich ist für Don Juan als Libertin das Prinzip der variatio delectat, dass also erst die ständige Veränderung des Liebesobjekts die Lust garantiere. Dies konnte Louis XIV. erfreuen, der in seinen ungezählten Liebesverhältnissen davon reichlich Gebrauch machte, nicht aber die Vertreter der religiösen wie gesellschaftlichen Ordnung bei Hofe. Der Don Juan Molières, so sehr sich dieser auch scheinbar und heuchlerisch den Regeln des Verhaltens eines honnête homme unterwarf, musste wie eine starke Provokation auf diese Kräfte wirken.

Genau hier, bei der Anrufung des Prinzips der variatio delectat, gäbe es die wohl überzeugendste und einleuchtendste Anschlussmöglichkeit für die Theorien des Göttlichen Marquis, des Marquis de Sade, dessen Werke im 19. und 20. Jahrhundert in allen Giftschränkchen der Schriftsteller vorhanden waren. Heute finden sie sich nicht mehr dort, sind sie doch seit den sechziger Jahren nicht zuletzt auf Grund der Studien eines Roland Barthes kanonisiert und in den Schulunterricht in Frankreich aufgenommen. Dennoch haftet dem Divin Marquis auch in Deutschland zu Unrecht ein anrüchiges Bild an, von dem sich der französische Schriftsteller wohl erst in einem weiteren Jahrhundert befreien können wird.

Es ist sicherlich ein wenig kühn, vom Don Juan Molières und dem französischen 17. Jahrhundert zwei Verbindungslinien in das europäische 18. Jahrhundert zu ziehen - zum einen zu Giacomo Casanova und zum anderen zur Figur von Sade. Doch wir bekommen auf diese Weise die grundlegenden Traditionslinien besser in den Griff, welche die europäischen Literaturen zweifellos durchziehen. Damit sei nicht betont, dass sich eine direkte Linie von unserem Zitat aus Molières Dom Juan zu Casanova und Sade ziehen ließe, wohl aber eine vermittelte und komplexe, die in ihrer Wirkmächtigkeit keineswegs geringer ausfällt als eine

6 Vgl. hierzu die klassische Studie von Auerbach, Erich: La cour et la ville. In (ders.): Vier Untersuchungen. zur Geschichte der französischen Bildung. Bern: A. Francke Verlag 1951, S. 12-51. 
direkte Filiation. Der Aufschrei der Kirche angesichts von Molières Dom Juan lässt sich auch nachträglich nicht rechtfertigen, wohl aber verstehen. Doch sehen wir uns dies einmal in aller gebotenen Kürze näher an!

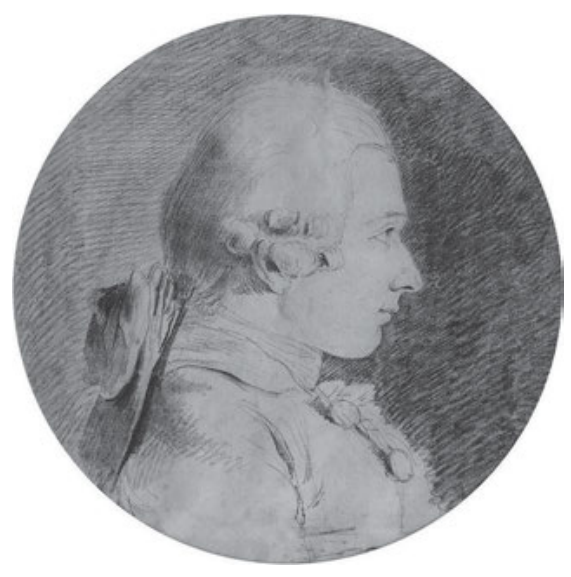

Abb. 71: Donatien Alphonse François de Sade, genannt Marquis de Sade (Paris, 1740 - SaintMaurice bei Paris, 1814).

Die Sade-Studien von Roland Barthes haben das Bild eines geradezu strukturalistischen Autors entworfen, der systematisch und methodisch vorging, der die Grenzen der körperlichen, objekthaften Kombinationsmöglichkeiten zu erforschen trachtete und der niemals die Wiederholung ein und derselben Liebessituation und Liebesstellung in seinen Schriften akzeptierte. ${ }^{7}$ Auf diese Weise entwickelte de Sade eine durchaus physisch und physiologisch gemeinte Kombinatorik der Liebe, die im Grunde einige der Grundannahmen Don Juans teilt und in der variatio den eigentlichen Urgrund für die Lust erblickt.

Zugleich verlagert und verdoppelt Sade den Schwerpunkt der Leidenschaft und der Passion. Es geht nicht länger um den Prozess der strategisch vorbereiteten und geplanten Eroberung, sondern um die verschiedensten Formen der Inbesitznahme von Körpern oder, um es etwas stärker zu sagen, von Körper-Objekten. Wir haben es hierbei mit einer ebenfalls schier unendlichen Abfolge von possessions und Stellungen zu tun, zugleich mit einer gezielten Verlagerung des Leidens und damit der Passion in den Vollzug der Liebe und des Liebesaktes selbst. Diese Passion ist auf den Leib des Subjekts und dessen Lust gerichtet, wobei simultan, wenn auch nicht notwendig im selben Körper des Anderen höchste Lust und höchstes Leiden sowie das Leiden an der Lust zum Vollzug und zum Höhepunkt gebracht werden.

7 Vgl. Barthes, Roland: Sade, Fourier, Loyola. Paris: Seuil 1971. 
Ich möchte Ihnen kurz einen Einblick in diese gezielte und wohlkalkulierte Kombinatorik von Stellungen anhand einer fast beliebig gewählten Stelle aus Sades Justine ou les malheurs de la vertu vor Augen führen und damit zugleich das Kapitel „Sade“ auch schon wieder abschließen, wäre es doch notwendig, sich wesentlich ausführlicher mit dem Marquis $\mathrm{zu}$ beschäftigen, um seinem Werk gerecht zu werden. Hier also die Stelle, in der Justine von ihren Peinigern berichtet:

\footnotetext{
Der dritte hieß mich auf zwei voneinander entfernte Stühle steigen und setzte sich darunter, erregt von der Dubois, die an seinen Beinen platziert war, und er liess mich vorbeugen, bis sein Mund sich quer zum Tempel der Natur befand; Sie könnten sich niemals vorstellen, Madame, was dieser obszöne Sterbliche zu begehren wagte; ich musste, ob nun Lust oder nicht, diese leichten Bedürfnisse befriedigen ... Gerechter Himmel! Welch depravierter Mensch kann denn auch nur einen Augenblick lang Lust bei solchen Dingen empfinden! ... Ich machte, was er wollte, ich überschwemmte ihn, und meine vollständige Unterwerfung erreichte bei diesem furchtbaren Menschen eine solche Trunkenheit, welche ohne diese Infamie nichts ausgerichtet hätte. ${ }^{8}$
}

Ich gebe zu, dass ich mit Bedacht diese Stelle ausgewählt habe, da sie zwar das ist, was in den Vereinigten Staaten als sexually explicit bezeichnet wird, zugleich aber nichts direkt benennt, was - so hoffe ich - bei Ihnen Anstoß erregen könnte. Gewiss, wir sind nicht mehr im Heidelberg der sechziger Jahre, wo die Erwähnung des „Göttlichen Marquis“ durch den noch jungen Erich Köhler das Missfallen der Studierenden erregte und es Eier und Tomaten gehagelt haben soll, um die depravierte bürgerliche Literaturwissenschaft dieses linken Professors zu geißeln. Erich Köhler hat, soviel darf man sagen, unter diesem Missverständnis zeit seines Lebens sehr gelitten, auch noch, als er die Universität Heidelberg geradezu fluchtartig verließ und an die Universität Freiburg wechselte, wo alles rund um die Achtundsechziger-Generation etwas ruhiger zu sein schien. So hoffe ich, Ihnen diese Passage zumuten zu können, da sie ein wichtiges Segment des Liebesbegehrens abdeckt, das nicht im Zentrum unserer Vorlesung steht, wohl aber nicht unerwähnt bleiben soll.

Was ich Ihnen zeigen wollte, ist die präzise und bewusste Kombinatorik, die - wie Roland Barthes angeführt hat - der gesamten Sade'schen Lusttheorie zu Grunde liegt. Barthes hatte ein geradezu strukturalistisches Verhältnis zu Sade, dessen Szenerien er damit gleichsam die Spitze nahm und einen Perspektivenwechsel in den Sade-Studien herbeiführte. Dies ist zweifellos ein Thema - die

8 Sade, Donatien Alphonse François de: Justine ou les Malheurs de la vertu, „en Hollande chez les Libraires associés“. Paris: Girouard 1791, S. 54 f. 
Kanonisierung Sades und dessen Überführung in einen Schulbuchautor - das sich näher auszuführen lohnte, allein mir fehlt die Zeit dazu in einer Vorlesung, in welcher es um Liebe und um Lesen, ums LiebeLesen geht.

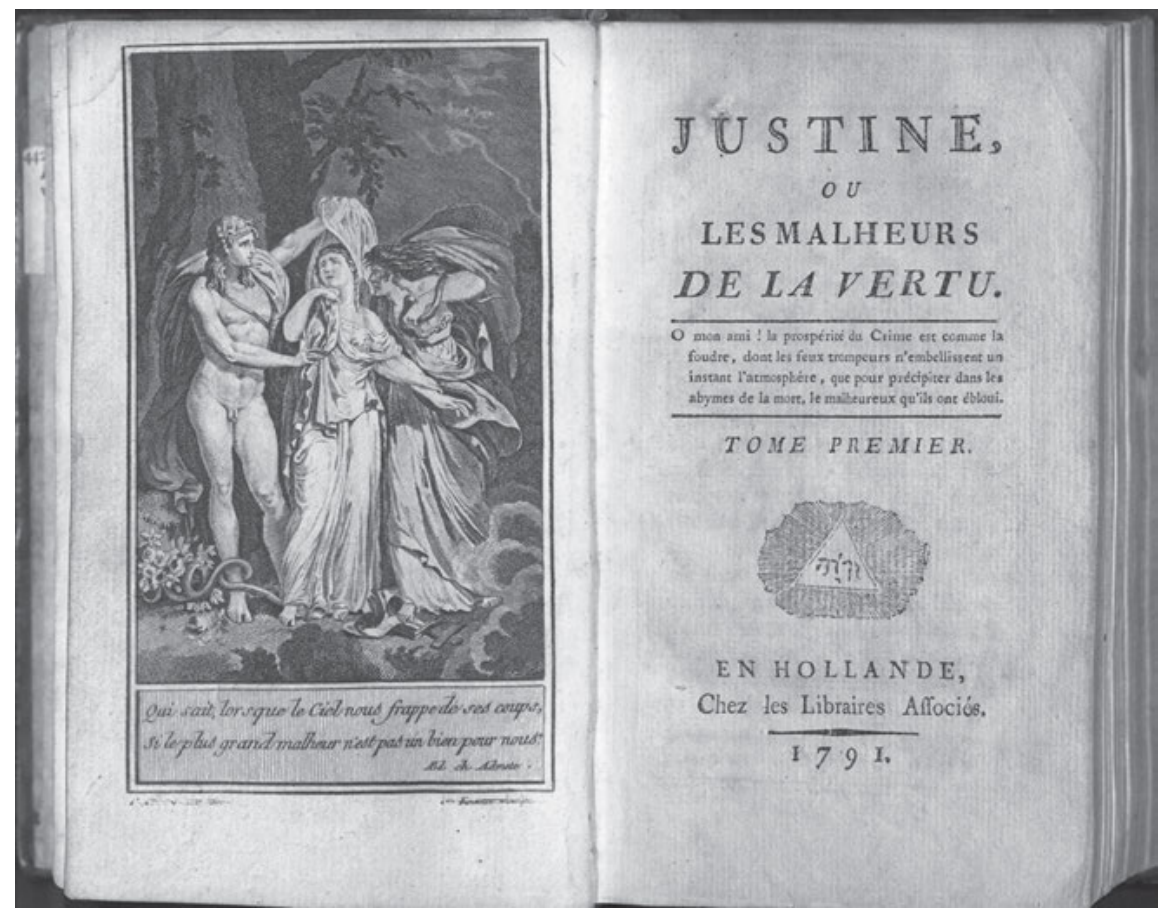

Abb. 72: Titelblatt der Erstausgabe von Justine ou les Malheurs de la vertu, 1791.

Freilich müssen wir etwas ergänzen, das Roland Barthes geflissentlich und ganz bewusst aus seinen Studien ausblendete. Denn es kommt noch ein wichtiges, vielleicht das wichtigste Element hinzu, das ebenfalls in dieser Szene deutlich hervortritt: Die völlige Unterwerfung des Körpers der Frau, eine totale Gewalt, welche über die Körper aller Frauen ausgeübt wird und eine wichtige Grundbedingung für die Lust der Protagonisten ist. Denn wir haben es bei de Sade mit den Exzessen und dem erotischen Überschuss einer patriarchalen und phallogozentrischen Ständegesellschaft im Ancien Régime zu tun, die auf diesen Seiten deutlich in den Fokus rückt. Ihr Gewaltexzess und ihre Unterwerfung der Frau werden bei de Sade konsequent ins Bild gesetzt.

All dies - und noch viel mehr - läuft im 18. Jahrhundert unter dem Stichwort Libertinage. Doch lassen Sie uns hier erst einmal einen Punkt machen! Denn ich möchte an dieser Stelle nicht den scheinbar so direkten Weg von Don Juan zum Marquis de Sade weiterverfolgen, auch wenn er zweifellos so naheliegend 
gewesen wäre, da Molières Deutung des großen Frauenverführers ohne jeden Zweifel in die Tradition der großen libertins und Freidenker gehört. Ich möchte vielmehr wieder zum Don Juan zurückkehren und damit auf eine Traditionslinie kommen, welche für die Behandlung des Stoffes von großem Gewicht war und uns zugleich zu seinen iberischen Ursprüngen zurückführt.

Diese abschließende Rückkehr erfolgt mit einem Theaterstück, das sicherlich weltweit, aber vor allem in Spanien und Lateinamerika, zu den bekanntesten Don Juan-Bearbeitungen gezählt werden darf: José Zorrillas Don Juan Tenorio. Diese Deutung des Stoffes wurde zumindest für die Spanier zur Verkörperung eines nationalen Mythos - im Guten wie im Schlechten. Man darf ohne Übertreibung sagen, dass Don Juan Tenorio noch heute jeder Spanierin und jedem Spanier grundlegend vertraut ist und nicht aufgehört hat, eine spanische Schulbuchlektüre zu sein.

Das Hauptwerk von José Zorrilla y Moral, der 1817 im altkastilischen Valladolid geboren wurde und 1893 in Madrid verstarb, erlebte seine Uraufführung am 28. März 1844 im Teatro de la Cruz in der spanischen Hauptstadt. Bei Zorrilla erhält Don Juan einen Gegenspieler und wird am Ende durch die unsterbliche Liebe der unschuldigen Inés zurück ins Reich der katholischen Kirche geholt, die dankbar das Versdrama - wie bereits erwähnt - an Allerseelen immer wieder aufführen ließ. Mit Zorrilla kehren wir entschlossen jedweder Libertinage den Rücken und besinnen uns zugleich auf die religiösen und iberischen Kontexte, die von Tirso de Molina herrühren. Wir befinden uns also erneut im eigentlichen ,Markenkern‘ dieses Stoffes.

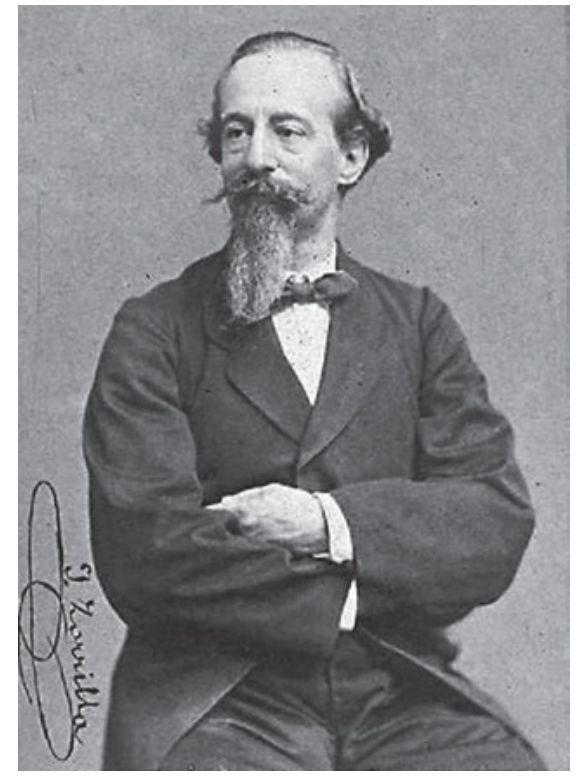

Abb. 73: José Zorrilla y Moral (Valladolid, 1817 Madrid, 1893), fotografiert im Jahr 1862. 
In den ersten vier Akten des Stückes erleben wir Don Juan wie eh und je als einen Draufgänger, der die Frauen verführt und sein prahlerisches Gehabe in vollen Zügen auslebt. Aber Hochmut kommt vor dem Fall. Zorrilla war durch kein klassisches französisches Regelwerk oder etwa durch die Einheit der Zeit behindert und ließ den zweiten Teil seines Dramas einige Jahre später spielen. Im letzten Akt wird er, der nun seine Sünden bereuend stirbt, auf Fürbitten der verstorbenen Inés erlöst und in den Himmel aufgenommen.

Den Erfolg des Stückes schrieb man häufig der Tatsache zu, dass Zorrilla seinem Protagonisten eine Vielzahl an Eigenschaften mit in die Wiege legte, die in Spanien als typisch spanisch gelten. Man geht wohl nicht zu weit mit der Behauptung, dass neben oder hinter der Figur von Don Quijote wohl Don Juan Tenorio die zweite große Verkörperung von Spanien und den Spaniern ist, die wir in der hispanischen Literatur ausmachen können. Dazu gehört sicherlich die Tatsache, dass Zorrilla auf sehr überzeugende Weise an die Traditionslinie des Siglo de Oro anknüpfte und auch darin den Erwartungen eines iberischen Publikums vollauf entsprach.

Bis jetzt ist in unserer Vorlesung Don Juan stets alleine zu Wort gekommen. Das soll sich nun ändern! Denn wir wollen eine Verführungsszene belauschen, die Don Juan Tenorio als erfolgreichen Frauenhelden und schamlosen Lügner ausweist. Die Bewunderung für letztere scheint etwas Überzeitliches $\mathrm{zu}$ sein, denken wir doch gerade an den Bereich der aktuellen Politik, wo sich dreiste Lügen beim Wahlvolk in aller Regel wieder auszahlen und witzig als ,alternative Wahrheiten' bezeichnet werden. Aber legen wir dieses traurige Thema rasch wieder beiseite und genießen wir diese Szenerie so, wie das spanische Publikum sie in aller Regel genossen hat, ohne dabei an Donald Trump, Boris Johnson und all die anderen politischen Führer und gefährlichen Spieler der gegenwärtigen Rechten zu denken, die uns mit ihren schamlosen Lügen verfolgen!

Wenden wir uns dem Text Zorrillas zu! Es ist die berühmte Passage der Verführung von Doña Inés zur Liebe in der dritten Szene des vierten Aktes, die wir uns ein wenig näher anschauen sollten:

\section{Don Juan.}

Ich hab' geschrieben,

Daß Ihr, aus der Gefahr befreit,

In meinem Schutze dann geblieben,

Und ruhig auf dem Lande seid.

D’rum sorge nicht, mein süßes Leben,

Und ruhe aus an dieser Stelle;

Nur einen kurzen Augenblick.

Denk' an die finstre Klosterzelle,

An Deinen Kerker nicht zurück. 
O, sage mir, Du Engelsbild,

Ob hier, wo stiller Friede wohnt, Nicht heller glänzt der Silbermond?

$\mathrm{Ob}$ freier nicht der Busen schwillt?

Und dieser Hauch, der in den Lüften

Sich leise regt, mit allen Düften

Der zarten Blumen angefüllt,

Die dort am schönen Ufer sprießen;

Und diese Wellen, rein und klar,

Die sanft und spielend weiter fließen,

Daß, unbekümmert um Gefahr,

Der Fischer bis zum Morgenroth

Sich schaukelnd singt im leichten Boot,

Das langsam hin und wieder geht;

O sage mir, Du holde Taube,

Ist's nicht wie meiner auch Dein Glaube,

Daß hier der Liebe Athem weht?

Und dieser Klänge, die der Wind

Aus all den tausend Blütenwipfeln,

Die er mit sanftem Hauch bewegt,

harmonisch uns herüberträgt;

Und dieser Töne Zauberfall

Aus dem Gesang der Nachtigall,

Die trillernd von Olivengipfeln

Dem nahen Tag entgegenschlägt,

Erfüllt von ewig heil'gem Triebe;

Du scheues Reh, Du lieblich Kind,

O sage mir, ist das die Liebe?

Und diese Rede, welche leis

Und schmeichelnd sich in's Herz Dir drängt,

Das schön an Don Juan's Lippen hängt,

Und noch nichts von dem Feuer weiß,

Das schöpferisch Dich neu belebet,

Ein Himmelsstrahl von Glück und Wonne!

O sage mir, Du meine Sonne!

Ist es nicht Liebe, die da wehet?

Und dieses flüss'ge Perlenpaar,

Das, wie Kristall so hell und klar,

An Deinen seid'nen Wimpern hängt,

Und langsam sich herniedersenkt

Aus diesen dunkeln Feueraugen,

Und ladet mich, es einzusaugen.

Das, wenn mein Mund nicht weg es küsste,

An eigner Glut vertrocknen müsste,

Und dieser Purpur Deiner Wangen,

Der in erhöhter Schönheit blüht,

Und zeugt von Sehnsucht und Verlangen, 
Ist es nicht Liebe, die da glüht?

O Ines, meiner Augen Licht!

Daß Du nicht meine Rede störest,

Daß Du sie ohne Zürnen hörest,

O sage, ist das Liebe nicht?

Verräth'risch wollte dieses Herz

In wildem Stolze sich erheben,

Als müsst" es nimmer sich ergeben,

Als ob es unbesiegbar bliebe;

Jetzt sieh'es hier zu Deinen Füßen,

Anbetend, wonnig zu genießen

Der Sklaverei so süßer Liebe!

\section{Doña Ines.}

O schweigt, Don Juan, ich muss vergehn!

Welch' neu Gefühl ist mir erwacht?

Nur sterbend hätte ich die Macht -

Ich fühl' es - ihm zu widerstehn.

Aus Mitleid schweiget, ich beschwöre!

Bei jedem Worte, das ich höre,

Scheint mir's, daß mir der Sinn vergeht

Und daß mein Herz in Flammen steht.

$O$ saget, einen Höllentrank

Habt Ihr mir heimlich eingegeben,

Ein Trank, der Frauentugend zwingt,

Sich willenlos Euch zu ergeben?

Habt Ihr vielleicht ein Amulet,

Mir unbewusst, in Euern Händen,

Unwiderstehlichen Magnet,

Daß sich mein Herz zu Euch muss wenden?

Oder hat gar der böse Feind

Euch seinen Zauberblick vertraut,

Und seiner Rede Schmeichellaut,

Die Liebe, die er Gott verneint?

Was soll ich thun, ich armes Kind,

Als auch in Eure Arme fallen,

Nachdem mein Herz Euch schon verfallen,

Das Ihr geraubt mit Wort und Blick?

Ich fühl's, ich kann nicht mehr zurück!

Es ist zu spät, Dir zu entfliehn;

Nicht wollen kann ich mehr, ich muss;

Es zieht mich zu Dir, wie den Fluss

Die Wellen hin zum Meere ziehn.

Wie Deine Nähe mich erfaßt,

Daß mir das eigne Selbst vergeht!

Wie Deine Worte mich umstricken!

Wie Deine Augen mich berücken! 
Dein Hauch vergiftend mich durchweht!

$\mathrm{O}$, so gewähre ritterlich

Was sich mein armes Herz erfleht:

Liebe oder tödte mich, Don Juan!

Liebe mich; denn ich bete Dich an! ${ }^{9}$

In diesem literarisch mit allerlei Versatzstücken versehenen Dialog, das sehen wir rasch, wird mit ungleichen Waffen gefochten. Denn wir erkennen hier die Figur eines Don Juan, der über alle Listen und Überraschungstricks eines Verführungsdiskurses verfügt, der über literarische Quellen und eine an der antiken Rhetorik geschulte Sprachbeherrschung gebietet und diese Möglichkeiten auch schamlos zur Verführung der unschuldigen Inés einsetzt. Dabei malt Don Juan seiner künftigen Geliebten vor dem dunklen Hintergrund der Klostermauern eine Welt und insbesondere eine Natur aus, die Liebe atmet, eine von Liebe durchtränkte Natur, die gleichsam die entsakralisierte Variante einer von der Liebe Gottes - und der Gottesliebe - erfüllten Welt darstellt. Er tut dabei nicht wesentlich mehr als einen antiken locus amoenus auszumalen und mit dem Hauch weltlicher Liebe zu durchtränken. Sie führen an, dass dies heute nicht mehr ausreichen würde, um wen auch immer zu verführen? Mag sein! Die Sprache der Liebe hat sich gewandelt, wie wir zweifellos konstatieren müssen. Aber für Doña Inés war es die richtige Sprache der Liebe, denn alles ist für sie nun von zärtlichen weltlichen Liebesgefühlen durchzogen und durchwoben.

In diesen Zusammenhang gehört schon die Anrede von Doña Inés als Liebesengel, wobei hier der Begriff des Engels seiner sakralen und zugleich auch geschlechtslosen Züge verlustig geht, gemeinsam mit ihm aber auch der Begriff der Liebe sowie das Objekt selbst, also die angesprochene Nonne in ihrem christlichen Kloster. Dieser Liebesengel soll nämlich gerade zur Zielscheibe einer entsakralisierenden Strategie werden, welche das weibliche Opfer zunächst aus dem Kloster hinaus und in die Arme Don Juans hineintreiben soll. Sie sehen, wie rhetorisch raffiniert in diesen Versen der „ángel de amor“, der Liebesengel, in die männliche Verführungsstrategie eingebaut ist, welche die Liebe der Nonne $\mathrm{zu}$ Gott in einem günstigen Augenblick nochmals in ihrer Liebesart verändert und auf den liebeshauchenden Verführer lenkt. Kein Zweifel: Don Juan ist belesen und zugleich gerissen, vor allem aber ein aufmerksamer und ausgezeichneter Leser einschlägiger Literatur.

9 Zorilla, José: Don Juan Tenorio. Religiös-phantastisches Drama in zwei Abtheilungen (Den Bühnen gebenüber als Manuscript gedruckt). Aus dem Spanischen übertragen durch G. H. de Wilde. Leipzig: F. A. Brockhaus 1850, IV, 3, S. 121-124. Originalzitat im Anhang aus Zorrilla, José: Don Juan Tenorio. Edición, prólogo y notas de Salvador García Castañeda. Barcelona: Editorial Labor 1975, 1a. parte, IV, 3, S. 158-162. 
Was der erprobte Frauenverführer also entwirft, ist nicht mehr und nicht weniger als ein locus amoenus nach antikem Vorbild, ein Lustort, an dem es an nichts fehlt. Sie finden den kleinen Fluss oder Bach, das klare transparente Wasser, die Blumen und Blüten sowie die keimenden Pflanzen, aber auch die Musik des vor sich hin trällernden Fischers. Diese letztgenannte Figur erweist sich bei näherer Betrachtung übrigens eher als ein durchaus verräterisches Bild Don Juans, denn mit ihr wird im Grunde auch schon die Dimension des Köders, des Lockmittels eingebaut. In der Folge ergeht gleich viermal die rein rhetorisch gemeinte Frage, ob in all diesen geschilderten Gefilden denn nicht wirklich alles Liebe atme. Beim vierten und letzten Mal freilich schlägt diese Liebe dann bereits in die Liebesbeziehung um und entfaltet ihre durchschlagende Wirkung auf Doña Inés, die sich im Liebesdiskurs des Verführers verheddert.

In der zweiten Liebesstrophe wird das Element Luft thematisiert, das bereits angesprochen wurde; und so findet sich die allumfassende und weltumpsannende Harmonie natürlich gerade auch in den Schwingungen der Luft, die eine Nachtigall auslöst - auch sie nicht mehr und nicht minder ein festes Element des tradierten und erlernten locus amoenus. In der zweiten rhetorischen Frage ist die Taube, die im Angesicht der römisch-katholischen Dreifaltigkeit noch immer etwas Göttlich-Sakrales besitzt, zum Reh geworden, was natürlich ebenfalls sehr schmeichlerisch gemeint ist. Aber auch hier ergibt sich eine differenzierte Ausdeutungslage, da das Reh, im spanischen Original die Gazelle, auf die Jagd verweist, welche auf die schöne junge Dame eröffnet ist. Doch noch einmal atmet alles Liebe.

In der dritten Strophe kommt Don Juan zur Sache, denn dieser ist er sich bereits sicher. In jenen Versen geht es selbstreferentiell um die Worte des Ich selbst. Und ebenso autoreferentiell geht es um die schöne Gestalt des Verführers mit Worten, zu dem sich - so Don Juan selber sehr zutreffend - Doña Inés bereits unwiderstehlich hingezogen fühlt. Don Juan, dies macht diese Passage deutlich, ist ein Wortkünstler; und literarische Verführer ohne ausgeprägte Behandlung der Wortkunst scheint es an sich gar nicht geben zu können. Ist Don Juan folglich ein Autor, ein Schriftsteller, ein Künstler?

Jedenfalls kennt er sich aus im weiten Feld der Literatur. Er ist sozusagen ein Spezialist in angewandter Literatur. Die Worte des Verführers aber bilden einen Diskurs, der in Brand setzt, einen discours incendiaire, welcher das Opfer - in Liebe selbstverständlich - entflammen lässt und zumindest binnen kurzer Zeit zur Schmelze bringt. Zugleich wird die Geliebte als Stern (hier in der deutschen Übersetzung als Sonne), als „estrella mía“, freilich wieder weiter entrückt, so weit, wie es ein Liebesengel im Himmel nur sein kann. Doch wie steht es mit der Wirkung, mit dem Impact bei der Schönen? 
Die vierte Strophe besingt hier bereits jene Wirkung dieses Diskurses der Liebe. Sie spricht von jenen beiden Perlen, die Tränen aus Inés’ Augen sind und die Rührung der schönen, unschuldigen jungen Frau anzeigen als ersten Lohn der rhetorischen Verführungskünste. Aber zugleich handelt es sich auch um einen wichtigen Verweis auf die Flüssigkeit, auf das Liquide, das in der Liebe auf allen Ebenen eine so herausragende Rolle spielt. Denn der Geliebte fühlt sich ganz in den Codes der Liebe und diese Codes manipulierend - aufgerufen, diese Liebesflüssigkeit aus ihrem Körper zu trinken, zu inkorporieren und in sich aufzunehmen. Da sind wir gar nicht mehr so weit von jener Szene entfernt, die der Marquis de Sade mit den Worten Justines so trefflich schilderte.

Selbstverständlich kann der Verführer, fast schon am Ziel, nun bereits ihre irdische Schönheit preisen und sie als „hermosa mía“ titulieren, als seine Schöne, die nun auch die entsprechende Farbe der Liebe auf ihren geröteten Wangen trägt. Sie wird ihm nun zum Spiegel und zum Licht seiner eigenen Augen, in deren Pupillen sich das kleine Püppchen der Geliebten reflektiert. Tauchten die Augen schon zuvor mit ihren Tränen als Spiegel der Seele auf, so widerspiegeln sie nun das geliebte Bild als Püppchen, als pupilla, das sich in den Pupillen des liebenden Gegenüber reflektiert weiß.

Das fünfte Erklingen des Zauberwortes Liebe, das nun endgültig auf die geliebte Inés übergesprungen ist, zeigt sie als Herrscherin über den zu ihren Füßen liegenden Don Juan. Der Verführer schlägt nun geschickt auch das Thema der Sklaverei, seiner eigenen Versklavung in Liebesdingen an. Die Metapher der Sklaverei aber weist bereits auf die absolute Abhängigkeit vom Anderen, auf eine völlige Hörigkeit, welche die zum Schein angebetete Inés in ihrer Antwort nun auch zum Ausdruck bringt und damit zugleich die Wirkung des erfolgreichen Liebesdiskurses von Don Juan bestätigt. Ihre Antworten enthalten eine Fülle von Aspekten, welche diese Wirkungen des Liebesdiskurses zeigen, aber zugleich auch die Stratageme der Verführung auf eine Inés selbst unbewusste Weise demaskieren und vorführen.

Denn Doña Inés ist von den lockenden Worten des Don Juan so hingerissen, dass sie ihnen nicht länger widerstehen kann und die Gefahr verspürt, andernfalls sterben zu müssen: Die Liebe und der Tod gehen hier jene intime Verbindung ein, die wir in unserer Vorlesung bereits thematisiert haben. Die körperlichen Orte, an denen der Liebesdiskurs Don Juans eingeschlagen hat, sind dabei deutlich bezeichnet. Zum einen handelt es sich um den Kopf, das Gehirn, den Verstand, die Rationalität, die außer Kraft gesetzt werden und in eine Verrückung, in ein Verrücktwerden, in Wahnsinn überzuspringen drohen. Inés selbst bezeugt, dass ihr Verstand wie gelähmt erscheint und sie handlungsunfähig macht.

Doch damit nicht genug! Denn der zweite Ort, der eigentliche Liebesort am menschlichen Körper, ist das Herz, das gezielt in Brand gesteckt wurde, was 
natürlich wesentlich leichter fällt, wenn die Vernunft zuvor ausgeschaltet wurde. Dies entspricht genau der Vorgehensweise des männlichen Verführers. Doña Inés erkennt sehr wohl das Infernalische, das sich der christlichen Nonne bemächtigt, da es ihr hier - in umgekehrter Bewegung - zu trinken gegeben und längst inkorporiert wurde. Es handelt sich um eine Art teuflisches oder höllisches Gift, das anders als die Tränen als Liebestrank hier nun die Abhängigkeit, die wirkliche Sklavenschaft auslöst und in die Hörigkeit, die absolute Abhängigkeit führt. Drangen die Tränen von innen nach außen als Spiegel der Seele, so dringt das infernalische Gift in den Körper der Nonne und führt sein Zerstörungswerk aus. Nicht Don Juan ist der Sklave, sondern Doña Inés eine Sklavin, die sich ihrem Sklavenhalter gänzlich unterwirft und um Liebe bettelt.

Blicken wir auf unsere ausführliche Beschäftigung mit Denis de Rougemont zurück, so sehen wir, dass das Thema des versehentlichen Liebestrankes für Tristan und Isolde nicht fern ist. Mehrfach wird die Metaphorik des Giftes von Inés bemüht, ohne dass die junge Frau gegen das ihre Widerstandskraft lähmende Gift vorgehen oder sich dessen Wirkung entziehen könnte. Sie ist Don Juan ausgeliefert.

Allerlei Vermutungen schließen sich an, wobei erneut das Satanische, der Teufelsbund, die magnetische Anziehungskraft, die nicht von dieser Welt allein sein kann, Erwähnung finden: Das Ausgeliefertsein der schönen Nonne ist unübersehbar und wird von ihr selbst auch thematisiert, ohne dass es doch zu Gegenmaßnahmen ihrerseits käme. Sie ist wie gelähmt im Spinnennetz des schamlosen Verführers, dessen Kalkül auf ganzer Linie siegt. Die Faszination des Gesichtssinnes hat etwas Teuflisches. Und so wird auch erkennbar, dass darunter ein alter christlicher Topos liegt. Erneut stoßen wir auf die Verführbarkeit des Menschen durch die Augen, die concupiscentia oculorum, welche alles Menschliche beinhaltet und zugleich auch dem Verderben weiht.

Zugleich erkennen wir noch einen anderen Befund im religiösen Spektrum denn vergessen wir nicht, dass es sich bei Doña Inés um eine Nonne handelt, die nun der katholischen Kirche und vor allem ihrem Bund mit Christus untreu wird. Satanisch ist die Verweigerung der Liebe gegenüber Gott, und satanisch ist daher auch eine weg von Gott auf die Menschen, auf die Frau, auf den Mann gerichtete Liebe, wie wir schon seit Beginn dieser Passage geahnt hatten. Die Unausweichlichkeit der befürchteten und doch ersehnten Liebesbeziehung wird in die Fluss-und-Meer-Metaphorik gekleidet, also in eine nicht länger vom Verstand, der Ratio, sondern von Naturkräften geleitete Bewegung der Auflösung, des Verlusts der eigenen Identität und Unabhängigkeit überführt.

So bleibt am Ende - da eine compasión, ein Mitleiden, aber auch eine wirkliche Mitleidenschaft im Grunde nicht zu erwarten sind - nur die Alternative der Zerstörung des Herzens oder einer wirklichen totalen Liebe, die gleichsam 
übermenschliche Dimensionen annehmen muss. An eben diesem Punkt zeichnet sich auch schon die Lösung des Konflikts durch Zorrilla ab. Denn zum einen kommt es selbstverständlich zu ersterem, also zu der zerstörerischen Kraft der Liebe, die Inés aus ihrem Kloster, aus ihrer virtud, der sie verlustig geht, und letztlich auch aus ihrem Leben reißen wird. Das Herz - als Ort der romantischen Liebe - wird ihr buchstäblich aus dem Leib gerissen werden, und die Schöne wird ihre Liebe zu Don Juan nicht in dieser Welt überleben. Mit ihrem Leben bezahlt sie für ihre irdische Liebe. Doch zum Glück gibt es da ja auch noch die göttliche Erlösung der Liebenden, die selbst den Sünder Don Juan noch in den Himmel führt!

Denn die Liebe Gottes, welche sich in der Frau inkarniert, rettet - und dies ist die interessante und originelle Wendung in Zorrillas Don Juan Tenorio - ebenso Doña Inés als auch Don Juan. Letzterer ist im zweiten Teil des Stückes längst dem Schrecken und einer einsetzenden Reue angesichts seiner Missetaten, die er selber aufzählt, verfallen. Mit einem Credo an die Adresse des Allmächtigen wendet er sich in der letzten Szene an den Himmel, freilich in der Überzeugung, dass es für seine Rettung zu spät ist. Doch es kommt anders!

Denn urplötzlich steigt Doña Inés aus ihrem Grab und erklärt ihrem Liebhaber, es sei nicht zu spät: Er könne noch immer - und zwar gemeinsam mit ihr - den Weg des christlichen Seelenheiles finden. Die Frau wird hier als Vermittlerin göttlicher Kräfte zur Retterin der Seele des Mannes: die Frau als Heilsbringerin, als Heilerin, als Wunderbringende, als heilbringende Inkarnation übermenschlicher Kräfte, von Gottes Liebe gespeist. Dies ist die Apotheose der christlichen und göttlichen Liebe gleichermaßen, die ich Ihnen zumindest kurz zum Abschluss unserer Beschäftigung mit Don Juan Tenorio sowie der nach Giacomo Casanova zweiten Verführerfigur einmal vorführen möchte.

\author{
Don Juan. \\ Gnäd'ger Himmel! Doña Inés! \\ Doña Inés. \\ Geister, auf! Ihr mögt verfließen! \\ Nur sein Glaube konnte retten. \\ Kehrt zu Euern Ruhestätten! \\ Also ist es Gottes Wille. \\ Meine Seele ward gepenigt, \\ Daß die seinige sich reinigt, \\ Und in seiner Gnade Fülle \\ Hört der Ewige mein Rufen, \\ Schenkt mir Don Juan's Seligkeit \\ Hier an meines Grabes Stufen [...] \\ Wird es den Gerechten klar,
}


Daß allein es Liebe war,

Die Don Juan an meinem Grabe

Vom Verderben hat gerettet [...]

Don Juan.

Gnäd'ger Gott, Heil Dir und Preis!

In Sevilla wird es Allen

Morgen früh das Herz ergreifen,

Daß von meiner Opfer Händen

Ich zur Sühne bin gefallen.

Nur gerecht ist's! Aller Welt

Liege hier das Zeugnis offen:

Weil ein Augenblick der Reue

Doch noch darf Erlösung hoffen

Und uns führt zum Himmelspfade.

Daß auch Juan Tenorio's Gott

Ist der Gott der höchsten Gnade.

(Don Juan fällt zu Doña Inés Füßen und beide sterben. Aus ihrem Munde steigen ihre Seelen in Gestalt zweier glänzenden Flammen empor, welche beim Klange der Musik sich nach oben velieren. Der Vorhang fällt. $)^{10}$

In dieser Szenerie am Ende von Zorrillas berühmtem Theaterstück wird gleichsam der Ketzer, der Häretiker, der Libertin und ruchlose Frauenverführer wieder in die Kirche, in den Katholizismus, in die Gemeinschaft der Gläubigen und in die Gesellschaft zurückgeholt. Von diesem sicheren Ort der Ordnung aus tritt er in Begleitung der von ihm Verführten nicht die Höllenfahrt - wie bei Tirso de Molina - an, sondern wendet sich nach oben, gen Himmel, um - wohl über den Umweg des Fegefeuers - seinen finalen Aufstieg in die Gemeinschaft mit den Seligen und natürlich auch mit Doña Inés anzutreten. die Gültigkeit der göttlichen Ordnung und zugleich auch der Lehren der Kirche werden von ihm vollauf bestätigt.

Damit tritt eine andere Liebe, die Gottesliebe, an die Stelle der fleischlichsündigen Liebe Don Juans zu den Frauen. Zugleich setzt sich die Tradition der christlichen Liebe gegen die Tradition der häretischen, gesellschaftsgefährdenden, stets auf einer Art Passion beruhenden Liebeskonzeption durch: Don Juan Tenorio und Doña Inés sind ein Paar. Das Mittel der Errettung aber ist die Frau, die im Anruf Don Juans gleichsam in einem Atemzug mit Gott genannt und damit zur quasi göttlichen Frau, Mutter und Beschützerin wird. Auf diese Weise wird aus der geschändeten Frau Doña Inés, die ihrem Gelübde und ihrer klösterlichen Gemeinschaft untreu wurde, doch noch die Heilige, die auf ihrem Weg durch die Liebesstratageme und die Machenschaften Don Juans verführt worden war.

10 Zorrilla, José: Don Juan Tenorio, II, 3 und 4, S. 202-204. 
Die Frau ist jene Kraft, die nun Rettung und Erlösung bringt - wenn Sie so wollen eine spanische Spielart des Ewig-Weiblichen oder jener heiligen Iphigenie der Humanität, wie sie Goethe in seiner Iphigenie auf Tauris entwickelt hatte. Wir sehen bei Zorrilla freilich eine Liebeskonzeption, die - auch in ihrer Interpretation des Katholizismus - deutlich romantische Züge trägt und die wir uns im weiteren historischen Fortgang unserer Vorlesung folglich erst noch erarbeiten müssen.

Es ist in unseren Ausführungen aber offenkundig geworden, welches Gewicht dem Don Juan-Stoff innerhalb der europäischen Literaturen seit Tirso de Molina zukommt und wie sehr er - als literarische Inkarnation einer ausschließlich literarischen und nicht historischen Figur - die Figuren der Liebe im Abendland grundlegend geprägt hat. Die Psychologisierung Don Juans oder seine Stilisierung zum Suchenden, zum Philosophen, soll uns hier nicht interessieren, beschränken wir uns doch im gewählten Zusammenhang auf den spanischen Bereich, der eine solche Auslegung des Stoffes kaum kennt.

Die Figur des Verführers in der Literatur, wie sie seit Tirso de Molina unter dem Namen Don Juans präsent ist, besitzt sehr eigene Züge und kann beim besten Willen nicht in eine emanzipatorische, die tradierten Geschlechterbeziehungen aufbrechende Dimension überführt werden: $\mathrm{Zu}$ sehr sind in den Don Juan-Stoff oder vielleicht mehr noch Don Juan-Mythos - Festschreibungen des Männlichen und des Weiblichen sowie deren Fixierung und bisweilen Radikalisierung eingegangen. Diese fixierten Geschlechteridentitäten und Geschlechterbeziehungen sind ebenso im ersten wie auch noch im zweiten Teil von Zorrillas Don Juan Tenorio evident.

In dieser allzu klaren Geschlechterordnung dürfte auch der Grund dafür liegen, warum Fanny Rubio in ihrem langen Essay zur Liebe und zu El embrujo de amar den Don Juan-Stoff als Spanierin zwar nicht vermeiden konnte und auch nicht ausklammerte, zugleich aber im spanischen Bereich auf eine bestimmte Lektüre von Fernando de Rojas' Celestina und dort insbesondere auf die Rolle Melibeas - „Yo soy la que gozo“ - zurückgriff. Denn bei Don Juan gibt es auf Seiten der Frauen weder Erfüllung noch Lust - es sei denn die Lust am eigenen Untergang, an der eigenen Auflösung im Anderen, wie es die Metaphorik von Doña Inés treffend umschrieb: In der Ausmündung des Flusses ins Meer löst sich der Fluss spurlos auf. 